Original Research Article

\title{
Analysis of prescription pattern of antihypertensives in various stages of chronic kidney disease
}

\author{
Prabitha P. ${ }^{*}$, Reshmi T. R. ${ }^{1}$, K. P. Jayakumar ${ }^{2}$
}

${ }^{1}$ Department of Pharmacology, Government Medical College, Kottayam, Kerala, India ${ }^{2}$ Department of Nephrology, Government Medical College, Kottayam, Kerala, India

Received: 24 December 2018 Accepted: 29 January 2019

\section{*Correspondence to:}

Dr. Prabitha P.,

Email: drprabisree@gmail.com

Copyright: (C) the author(s), publisher and licensee Medip Academy. This is an openaccess article distributed under the terms of the Creative Commons Attribution NonCommercial License, which permits unrestricted noncommercial use, distribution, and reproduction in any medium, provided the original work is properly cited.

\begin{abstract}
Background: Chronic kidney disease (CKD) is an emerging health problem and is one of the major causes of mortality. Hypertension is closely linked with CKD and both these conditions cause severe cardiovascular events. Hence blood pressure control is pertinent in all stages of CKD. This plays a major role in preventing its progression to end stage kidney disease and death. The objectives of the study were to analyse the class, dosing schedule of antihypertensive prescribed in Chronic Kidney Disease and the incidence of monotherapy and combination therapy.

Methods: This study designed as a cross sectional study was conducted in Nephrology department of a tertiary care center and antihypertensive prescription pattern of 364 CKD patients was analyzed. Demographic details, the co-morbid factors and the details of drugs received by each patient were recorded from their outpatient/ inpatient charts. Data collected were entered in MS excel sheet and descriptive analysis done using SPSS software.

Results: Calcium Channel Blocker (CCB) was the most commonly prescribed antihypertensive $(70.6 \%)$ in all stages and the most common CCB was Cilnidipine (54\%) with the dosing schedule of $20 \mathrm{mg}$ twice daily (56.4\%). Incidence of combination therapy was $71.7 \%$ and $\mathrm{CCB}+\mathrm{AA}$ (Alpha agonist) was the commonest combination prescribed in all stages except stage 1 .

Conclusions: CCBSs were widely prescribed as antihypertensive in CKD irrespective of the stages. Cilnidpine was the routinely prescribed CCB and seemed to be well tolerated by the patients. The protocol followed in this tertiary care center was in accordance with the standard guidelines by Kidney Disease Improving Global outcomes 2012.
\end{abstract}

Keywords: Cilnidipine, Hypertension, Kidney disease improving global outcomes guidelines, Renal failure

\section{INTRODUCTION}

Chronic Kidney Disease (CKD) is defined as a condition with decreased kidney function shown by a Glomerular Filtration Rate (GFR) of less than $60 \mathrm{ml} /$ minute per $1.73 \mathrm{~m}^{2}$, or markers of kidney damage (abnormal urine sediments, renal imaging/ biopsy results) or both, of at least 3months duration, regardless of the underlying cause. ${ }^{1}$ The prevalence of CKD in India is approximately $13 \%$. Once kidney impairment sets in, it progresses to End Stage Kidney Disease (ESKD)and this population is very much vulnerable to cardiovascular events. The risk of death is proportional to the worsening kidney function and cardiovascular diseases. Diabetes and hypertension are commonly associated with CKD. Therefore it is important to identify and prevent them. ${ }^{2}$ Hypertension is one of the risk factors which can be controlled and its prevention is one of the methods to prevent progression of CKD to ESKD. ${ }^{3,4}$ The relationship between CKD and hypertension is cyclic as CKD can contribute to or cause hypertension. Progressive renal disease can exacerbate uncontrolled hypertension due to volume expansion and increased systemic vascular resistance. Elevated blood pressure (BP) leads to damage of blood vessels within the kidney, as well as throughout the body. This damage impairs the kidney's ability to filter fluid and waste from the blood, leading to an increase of fluid volume in the 
blood-thus causing an increase in BP. ${ }^{5}$ Multiple guidelines discuss the importance of lowering blood pressure to slow the progression of renal disease and reduce cardiovascular morbidity and mortality. However, in order to achieve and maintain adequate BP control, most patients with $\mathrm{CKD}$ require combinations of antihypertensive agents; often up to three or four medication classes may need to be employed. Management depends on stages of disease severity, which are assessed from GFR, albuminuria, and clinical diagnosis (cause and pathology). CKD is divided into 5 stages according to disease severity. ${ }^{6}$ This study aims to analyse various types of antihypertensives used in different stages of CKD. Early and proper management slows CKD progression, reduce risk of cardiovascular disease, and thus improve quality of life.

\section{METHODS}

This study was designed as a cross sectional study. This was conducted in Nephrology department of a 1400 bedded tertiary care centre in central Kerala. Institutional ethics committee approval was obtained and the IRB no is $129 / 2016$. Based on the study by Bhanupriya et al, in which the maximum number $(39.5 \%)$ of patients received Calcium channel Blocker (CCB) as antihypertensive, the sample size was calculated to be $364 .{ }^{7}$ The study period was between August 2017 to January 2018. The study population included the patients in both outpatient and inpatient units of Department of Nephrology of a tertiary care centre. Patients of all age group, both sexes diagnosed by nephrologists as Chronic Kidney Disease and on antihypertensives were recruited for the study till sample size was reached. Patients with acute renal injury were excluded from the study. Patients were recruited in a consecutive manner during Out Patient (OP) days of the department which was twice in a week and their prescription pattern was recorded. A retrospective analysis of medical records of CKD patients admitted to the institution was traced once a week using the international Classification of Disease code - 10(N18). Around 196 patients from outpatient and 168 from in patient departments were enrolled for the study through this procedure. Data collection was done using a structured proforma approved by Ethics Committee. All relevant data including demographic details, co morbid factors, stage of CKD, Blood pressure, laboratory data (Histopathological diagnosis, renal function tests) and details of antihypertensive and other concomitant drugs received by each patient were recorded in the proforma. Drug details included the generic name, category, dose, frequency and duration of antihypertensives prescribed. Details of other supportive therapy were also taken down. All data were entered in MS Excel. Descriptive analysis was done using SPSS 16 software to learn the result.

\section{RESULTS}

This study analyzed the prescription pattern of 364 CKD patients who were on antihypertensives. Among these 261
(71.7\%) patients were males and 103 (28.3\%) patients

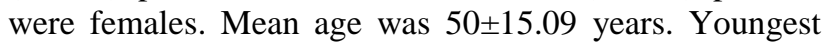
patient was 5 years and the eldest one was 86 years old. Maximum number of patients $(n=150,41.2 \%)$ were in age group of 51-65years as shown in Figure 1. Various co morbid factors/etiology were encountered. The most common co morbidity was type 2 diabetes mellitus $(\mathrm{n}=156,43 \%)$ and the other co morbidities are as shown in Table 1.

\section{Table 1: Distribution pattern of co morbid factors/Etiology among CKD patients.}

\begin{tabular}{|ll|}
\hline Comorbid factors/ etiology & Number \\
\hline Type 2 diabetes mellitus & $156^{*}$ \\
\hline IgAnephropathy & 54 \\
\hline Severe variants of nephrotic syndrome & 51 \\
\hline Vascular causes & 45 \\
\hline Coronary arterial disease (CAD) & 37 \\
\hline Nephrolithiasis & 11 \\
\hline Polycystic kidney dieases & 11 \\
\hline Tubulointerstitial diseases & 10 \\
\hline Autoimmune diseases & 10 \\
\hline Hypothyroidism & 8 \\
\hline Other glomerular diseases & 8 \\
\hline $\begin{array}{l}\text { Non steroidal anti inflammatory drugs } \\
\text { induced }\end{array}$ & 4 \\
\hline Pulmonary hypertension & 2 \\
\hline Inflammatory bowel disease & 2 \\
\hline Atypical haemolytic syndrome & 2 \\
\hline Chronic hepatitis B & 1 \\
\hline Type 1 diabetes mellitus & 1 \\
\hline
\end{tabular}

*More than one co morbid factors seen in prescriptions.

All classes of antihypertensives were prescribed and the most common category of antihypertensive prescribed was Calcium channel blockers (CCB). Out of the 364 prescriptions $257(70.6 \%)$ contained CCB. Maximum proportion of prescribed CCB was Cilnidipine $(n=140$, $54 \%)$ and dose was Cilnidipine $20 \mathrm{mg}$ twice daily $(\mathrm{n}=79$, $56.4 \%$ ). The prescription pattern is as shown in Figure 2 and Table 2 .

Among 364 prescriptions, 261 (71.7\%) were combination therapy and 103 (28.3\%) were monotherapy. Diverse types of combinations assorting the different classes of antihypertensives were observed. Around $12.6 \%$ of combinations were $\mathrm{CCB}+\mathrm{Alpha}$ Agonist (AA) and that was the most routinely prescribed combination therapy. Commonly prescribed $\mathrm{CCB}$ in this combination was Nifedipine $(60 \%)$ with dose $20 \mathrm{mg}$ three times daily and AA was clonidine $(95 \%)$ with dose 100 microgram three times daily. Second most common was $\mathrm{CCB}+$ Diuretic (D) $(8 \%)$. The most common antihypertensive drug used as monotherapy was CCB $(12.9 \%)$ and the commonest CCB was Cilnidipine (46\%) and dose used was $10 \mathrm{mg}$ twice daily. Second most common type used as monotherapy was $\mathrm{AT}_{1}$ receptor blocker (ARB) (4.4\%). 
Table 2: Prescription pattern of antihypertensive in CKD.

\begin{tabular}{|c|c|c|}
\hline $\begin{array}{l}\text { Class of } \\
\text { antihypertensive }\end{array}$ & Name of drug & $\begin{array}{l}\text { Number of } \\
\text { prescriptions } \\
(\%)\end{array}$ \\
\hline \multirow{5}{*}{ CCB (257) } & Cilnidipine & $140(54)$ \\
\hline & Nifedipine & $97(38)$ \\
\hline & Amlodipine & $15(6)$ \\
\hline & Benidipine & $3(1)$ \\
\hline & Diltiazem & $3(1)$ \\
\hline \multirow{2}{*}{ Alpha agonists (150) } & Clonidine & $136(91)$ \\
\hline & Moxonidine & $14(9)$ \\
\hline Alpha blockers (81) & Prazosin & $81(100)$ \\
\hline \multirow{6}{*}{ Beta blockers (105) } & Carvedilol & $38(36)$ \\
\hline & Nebivalol & $31(30)$ \\
\hline & Metoprolol & $23(22)$ \\
\hline & Atenolol & $8(8)$ \\
\hline & Bisoprolol & $4(4)$ \\
\hline & Propranolol & $1(1)$ \\
\hline \multirow{4}{*}{ Diuretics (122) } & Torasemide & $62(51)$ \\
\hline & Furosemide & $56(46)$ \\
\hline & Spiranolactone & $3(2)$ \\
\hline & Metolazone & $1(0.8)$ \\
\hline \multirow{3}{*}{$\mathrm{ARB}(45)$} & Losartan & $21(47)$ \\
\hline & Telmisartan & $20(44)$ \\
\hline & Azilsartan & $4(9)$ \\
\hline PCO (4) & Nicorandil & $4(100)$ \\
\hline ACE inhibitor (1) & Enalapril & $1(100)$ \\
\hline Vasodialator (1) & Dihydralazine & $1(100)$ \\
\hline
\end{tabular}

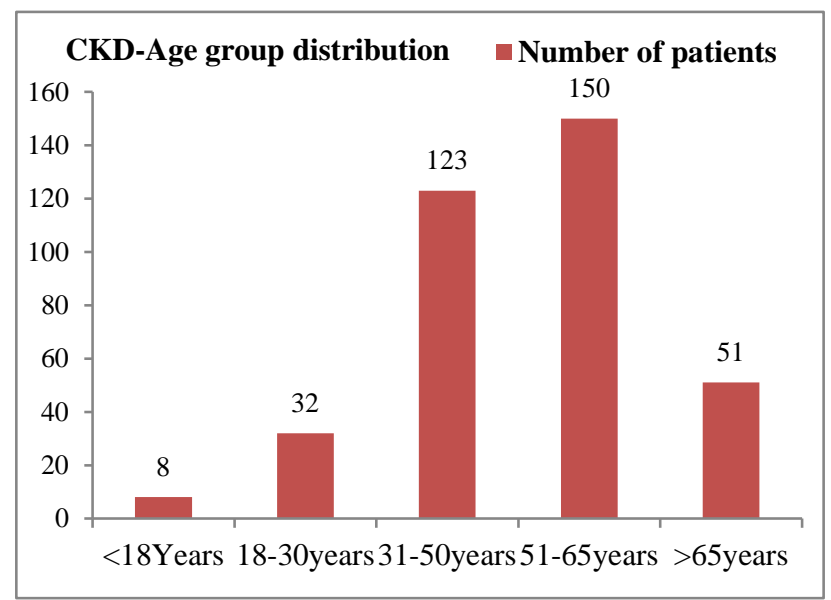

Figure 1: Age group distribution of CKD patients.

One hundred and fifteen (32\% of) patients were in Stage 5 and myriad of combinations were prescribed to them. Patients received 1-5 drugs as antihypertensives and included all classes. Around 91 out of 115 received CCB in combination as well as single drug. Commonest combination seen in CKD stage 5 was again $\mathrm{CCB}+\mathrm{AA}$ (8\%). About $14 \%$ patients of stage $4,12 \%$ of Stage 3, $20 \%$ of Stage 2 received the same combination. Four patients recruited were in stage 1 . Among these, two patients received the combination $\mathrm{CCB}+\mathrm{D}$. The prescription pattern seen in various stages were as shown in Table 3.

Table 3: Prescription pattern in various stages of CKD.

\begin{tabular}{|c|c|c|}
\hline $\begin{array}{l}\text { Stage (total } \\
\text { number of } \\
\text { prescriptions) }\end{array}$ & $\begin{array}{l}\text { Top } 5 \text { combination } \\
\text { therapy in various } \\
\text { stages (Number of } \\
\text { Prescriptions) }\end{array}$ & $\begin{array}{l}\text { Pattern of } \\
\text { Monotherapy } \\
\text { (Number of } \\
\text { Prescriptions) }\end{array}$ \\
\hline Stage 5 (115) & $\begin{array}{l}\mathrm{CCB}+\mathrm{AA}(10) \\
\mathrm{CCB}+\mathrm{AA}+\mathrm{BB}(9) \\
\mathrm{CCB}+\mathrm{D}(7) \\
\mathrm{CCB}+\mathrm{AA}+\mathrm{AB}+\mathrm{BB}(6) \\
\mathrm{CCB}+\mathrm{BB}(6)\end{array}$ & $\begin{array}{l}\text { CCB (10) } \\
\mathrm{BB}(5) \\
\mathrm{D}(4) \\
\mathrm{AA}(3) \\
\mathrm{ARB}(1)\end{array}$ \\
\hline Stage 4 (100) & $\begin{array}{l}\mathrm{CCB}+\mathrm{AA}(14) \\
\mathrm{CCB}+\mathrm{D}(12) \\
\mathrm{CCB}+\mathrm{BB}(6) \\
\mathrm{CCB}+\mathrm{AA}+\mathrm{D}(5) \\
\mathrm{CCB}+\mathrm{AB}(5)\end{array}$ & $\begin{array}{l}\text { CCB (13) } \\
\text { D (5) } \\
\text { ARB (4) } \\
\text { AA (4) } \\
\text { AB (2) } \\
\text { BB (1) }\end{array}$ \\
\hline Stage 3 (95) & $\begin{array}{l}\mathrm{CCB}+\mathrm{AA}(12) \\
\mathrm{CCB}+\mathrm{D}(10) \\
\mathrm{CCB}+\mathrm{AA}+\mathrm{BB}(7) \\
\mathrm{ARB}+\mathrm{D}(3) \\
\mathrm{CCB}+\mathrm{AB}(3)\end{array}$ & $\begin{array}{l}\mathrm{CCB}(12) \\
\mathrm{ARB}(6) \\
\mathrm{BB}(5) \\
\mathrm{D}(3) \\
\mathrm{AA} \mathrm{(3)} \\
\mathrm{AB}(1)\end{array}$ \\
\hline Stage $2(50)$ & $\begin{array}{l}\mathrm{CCB}+\mathrm{AA}(10) \\
\mathrm{CCB}+\mathrm{BB}(3) \\
\mathrm{CCB}+\mathrm{AB}(3) \\
\mathrm{ARB}+\mathrm{AB}(3) \\
\mathrm{CCB}+\mathrm{D}(1)\end{array}$ & $\begin{array}{l}\mathrm{CCB}(12) \\
\mathrm{ARB}(5) \\
\mathrm{BB}(1)\end{array}$ \\
\hline Stage 1 (4) & $\mathrm{CCB}+\mathrm{D}(2)$ & $\begin{array}{l}\text { D (1) } \\
\text { ARB (1) }\end{array}$ \\
\hline
\end{tabular}

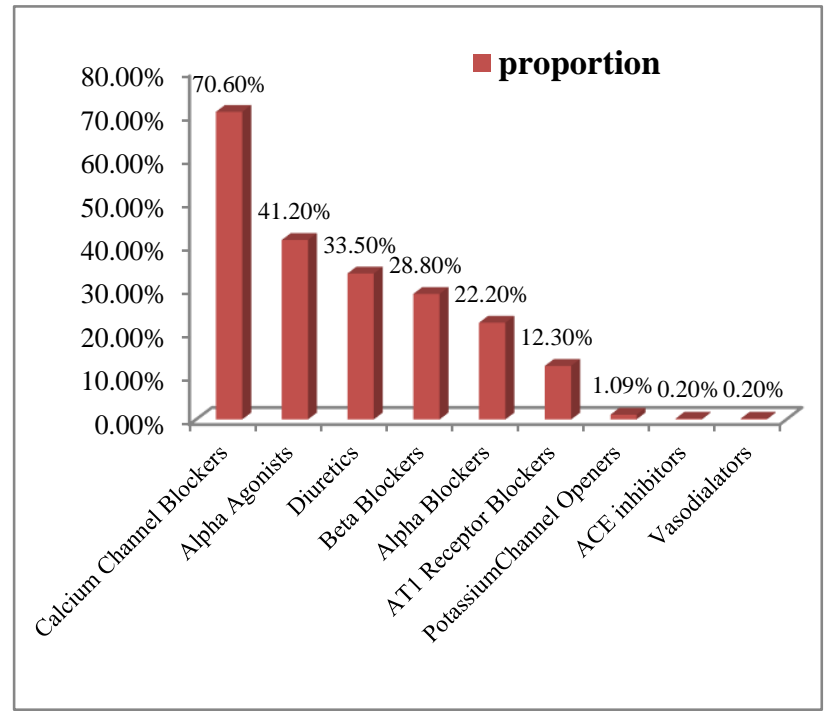

Figure 2: Prescription pattern of antihypertensives in CKD.

Out of the 156 diabetic patients 109 patients received CCB and cilnidipine (70 patients) was the regularly prescribed CCB. $50 \%$ of the elderly (>65 years) 
population in the study also received $\mathrm{CCB}$ both in combination as well as monotherapy. Out of 8 children ( $<18$ years) two patients received ARB and two patients received Diuretics as monotherapy.

Antiplatelet drugs, hypolipidemicdrugs, vitamins, phosphate binders, erythropoietin, oral hypoglycemics, insulin, proton pump inhibitors and glucocorticoids were also prescribed along with the antihypertensives. Patients received in total around 1-9 number of drugs. About 78 $(21.4 \%)$ patients received total of 5 drugs.

\section{DISCUSSION}

CKD is a global health problem and one of the risk factors for cardiovascular diseases. Prevalence of CKD is on the rise and hence its management is very relevant. In this study, male preponderance was noted among CKD patients. Females appear to have protection against CKD and its progression to ESKD. The prevalence of CKD among female population is less in reproductive years and increase 10 years later than in men. ${ }^{8}$ The unhealthy lifestyle and damaging effects of testosterone may lead to rapid deterioration of renal function in males whereas in females estrogen plays a protective role. ${ }^{9}$ Middle age population is maximally affected in this study as after 40 years glomerular filtration begins to fall by $1 \%$ per year. Besides this natural kidney ageing, hypertension, diabetes and cardiovascular events which cause renal injury start to crop up in this age group. ${ }^{10}$ Type 2 diabetes mellitus is a leading cause of CKD accounting for $30-50 \%$ of new cases of renal failure in the industrialized world and the same pattern was noticed in this study also. ${ }^{11}$

Hypertension is a strong risk factor for CKD and the existing guidelines recommend strict antihypertensive treatment. According to KDIGO guidelines there is no strong evidence to support the preferential use of any class of antihypertensive except in proteinuric CKD where angiotensin converting enzyme inhibitors (ACE-I)/ ARBs are chosen. In non proteinuric patients targets currently recommended in the general population be extrapolated to those with CKD. In this study CCBs were the topmost prescribed class of antihypertensive irrespective of the stages and resembled the prescription pattern observed in some other studies. ${ }^{7,12,13}$ They are one of the first line drugs in hypertension. CCBs do not accumulate in patients with impaired kidney function. The major subclasses are dihydropyridines (DHP) non-DHPs and benzothiazepines. The most frequently prescribed CCB in this study was cilnidipine which is a new (fourth) generation DHP. Cilnidipine blocks both L-type/N-type voltage gated calcium channels whereas other DHPs are strictly L-Type CCBs. By blocking the N-type channels in sympathetic nerves endings, cilnidipine suppresses the sympathetic over activity leading to dilatation of both afferent and efferent arterioles of the kidney and thus reducing intra glomerular pressure and proteinuria. Cilnidipine significantly reduces urinary albumin creatinine ratio unlike other DHPs which increases proteinuria. ${ }^{11}$ Additionally this drug reduced uric acid production without adversely affecting serum uric acid level and reduced urinary uric acid/ creatinine ratio. It is said that hypertension cause sympathetic over activity, reduced nitric oxide production from vascular endothelium due to insulin resistance and this can lead on to unrestricted production of hypoxanthines which are uric acid precursors in the skeletal muscle causing myogenic hyperuricemia. ${ }^{14}$ More over cilnidipine suppresses RAAS activation, oxidative stress and podocyte disorder in an experimental study using spontaneously hypertensive rats. $\mathrm{N}$-type calcium channels are present in podocytes. Clinically antiproteinuric effect continued at least for 6 months after treatment period. Cilnidipine5-20 mg once daily administration over 3 weeks reduced BP from $149 \pm 4 / 88 \pm 2$ to $141 \pm 3 / 82 \pm 2$. Hence there is no risk of hypotension or reflex tachycardia. Risk of pedal edema is also less with Cilnidipine. Cilnidipine $20 \mathrm{mg}$ twice daily was the frequently prescribed dose in this study. Cilnidipine reduced elevated morning $\mathrm{BP}$ which is associated with target organ damage. Cilnidipine 5-10 mg/day for 12 weeks improves insulin sensitivity and have a favorable effect on glucose metabolism. Hence this is preferred drug in diabetes also. ${ }^{15}$ In our study also 109 patients out of 156 received CCB. Among these $64 \%$ received cilnidipine.

Combination treatment is required for hypertension management in CKD according to the guidelines. In this study also combination therapy was commonly practiced. Though various combinations were spotted, $\mathrm{CCB}+\mathrm{AA}$ were a bit more frequently prescribed combination $(8 \%)$ as alpha agonists interact minimally with other antihypertensive and they are valuable as adjunct therapy for resistant hypertension in CKD patients. ${ }^{11}$

Larger number of patients were seen to be in later stages of CKD in this study as many prescriptions were entered from inpatient charts. The work group KDIGO has not formulated any recommendations according to stage of CKD. ${ }^{11}$ Despite the fact that Angiotensin Converting Enzyme Inhibitors (ACE-I) are the antihypertesives of choice in proteinuric $\mathrm{CKD}$ their use in practice appear to be fewer. ${ }^{7,14}$ ACE-Is reduce GFR as they dilate efferent arterioles which may be favorable in early stages of CKD as reduced intraglomerular pressure is protective. But in later stages this may be destructive when renal function is severely compromised and dialysis is in store. ${ }^{11}$ In our study the greater number of patients were in later stages of CKD and that explains the underutilization of ACE-I in the prescriptions. ARBs were used more regularly than ACE inhibitors may be because of the less tolerability of the latter. They were the second most common monotherapy in this study and prescribed principally in the early stages of CKD.

Presence of various co morbid factors and complications render polypharmacy inevitable as noted in this study. Use of cheaper drugs, convenient frequency of dosing and 
reduction in pill numbers by resorting to combination pills maximize the adherence of patients to therapy.

As this was a cross sectional study no follow up was done and patients' adherence to antihypertensive drug therapy was not noted. The study would have been more comprehensive if pharmaco-economic analysis was also done.

\section{CONCLUSION}

Even though all classes of antihypertensives were prescribed the commonest one being $\mathrm{CCB}$ and the most common CCB was cilnidipine. The prescription pattern observed has a resemblance with many other prescription pattern studies. Combination therapy was more frequent than mono therapy. $\mathrm{CCB}+\mathrm{AA}$ was the most routinely prescribed combination in all stages of CKD except stage 1. In general the prescription pattern observed was not deviating from KDIGO guidelines.

\section{ACKNOWLEDGEMENTS}

Authors would like to acknowledge Dr. Dhanya SP, Assistant Professor, Department of Pharmacology, Government Medical College, Kottayam.

Funding: No funding sources Conflict of interest: None declared

Ethical approval: The study was approved by the Institutional Ethics Committee

\section{REFERENCES}

1. Webster AC, Nagler AV, Morton RL, Masson P. Chronic kidney disease. Lancet. 2017;389(10075):1238-52.

2. Varma PP. Prevalence of CKD in India - Where are we heading? Indian J Nephrol. 2015;25(3)133-5.

3. Tozawa M, Iseki K, Iseki C, Kinjo K, Ikemiya Y, Takishita S. Blood pressure predicts risk of developing ESRD in men and women. Hypertension. 2003;41:1341-5.

4. Bakris GL, Ritz E. The message for world kidney day2009: hypertension and kidney disease: a marriage that should be prevented. Clin J Am Soc Nephrol. 2009;4(3):517-9.
5. Lettica Buffet, Charlotte Richetti. CKD and Hypertension a destructive combination. US Pharm. 2012:37(6):26-9.

6. The Renal Association. CKD stages. Available online at https://renal.org. Accessed on 15 November 2018.

7. Priya BB, Basavanna PL. Pattern of antihypertensive drug utilization among CKD patients in a dialysis unit of tertiary care hospital. IJBR. 2015;6:2455-6.

8. Iseki k. Gender difference in chronic kidney disease. Kidney Int. 2008;74(4):415-7.

9. Carrero JJ, Hecking M, Chesnaye NC, Jager KJ. Sex and gender disparities in the epidemiology and outcomes of chronic kidney disease. Nat Rev Nephrol. 2018;14(3):151-64.

10. Center for disease control and prevention. Chronic kidney disease surveillance system risk factor and theme: Age. Available at: https://nccd.cdc.gov. Accessed on 15 November 2018.

11. Kidney international supplements. Blood pressure management in CKD ND patients with diabetes mellitus. 2012;2(5):323-69.

12. Joseph N, Yogananda R, Bharathi. A study on prescription pattern of antihypertensive agents in chronic renal failure patients and assessment of medication adherence. Int J Pharm Sci Rev Res. 2017;45(2):72-5.

13. Ahmad R, Habib A, Rehman S. management of hypertension in patients with end stage renal disease leading to hemodialysis: a challenge. IJAM. 2016;3(4):790-8.

14. Uchida S, Takahashi M, Sugawara M, Saito T Nakai K, Fujita M, et al. Effects of N/L type calcium channel blocker Cilnidipine on nephropathy and uric acid metabolism in hypertensive patients with chronic kidney disease (J-CIRCLE study). J Clinhypertens (Greenwich). 2014;16(10):746-53.

15. Shete MM. Cilnidipine: Next generation CCB. J Assoc Physicians India. 2016;64:95-9.

Cite this article as: Prabitha $\mathrm{P}$, Reshmi TR, Jayakumar KP. Analysis of prescription pattern of antihypertensives in various stages of chronic kidney disease. Int J Basic Clin Pharmacol 2019;8:524-8. 